\title{
Long term outcome of treatment of end stage renal failure
}

\author{
P HENNING, ${ }^{*}$ L TOMLINSON, $\uparrow$ S P A RIGDEN,, G B HAYCOCK, $\ddagger$ AND C CHANTLER
}

From the *Department of Nephrology, Adelaide Children's Hospital, South Australia, and Departments of $\ddagger$ Paediatric Nephrology and †Psychology, Guy’s Hospital, London

SUMmaRY The most common causes of end stage renal failure in 46 children (mean age 11 years, range 4-14) treated between January 1972 and June 1977 were: reflux nephropathy $(n=12)$, cystinosis $(n=7)$, focal and segmental glomerulosclerosis $(n=6)$, and Schönlein-Henoch disease $(n=5)$. The quality of life, degree of renal function, and height attainment of the 31 survivors were assessed in June 1985, when their mean age was 22 years (range 14-27), using hospital records and a questionnaire designed to highlight social and psychological problems.

Twenty six patients had a functioning transplanted kidney. Average growth during treatment for all survivors was normal, but most were disappointed with their 'final height'. Though five patients had some form of disabling bone disease, all 31 could walk and 27 could run. Sixteen $(67 \%)$ were in full or part time employment and nine were living independently.

A group of 32 patients with juvenile onset diabetes treated at this hospital for a least five years were also asked to complete the questionnaire and of these, 17 responded. On average, their data could usefully be compared with those of cases of end stage renal failure. More of the diabetics had jobs, but most sexually mature patients with renal disease were concerned about their physical appearance and had not achieved any stable long term sexual relationships. We suggest that a poor body image resulting in low self esteem may be responsible for the deficiency and believe that further study in this group is warranted.

The first child entered the regular dialysis and transplant programme at Guy's Hospital in September 1968 , and the first 10 years' experience of this paediatric programme has been reported. ${ }^{1}$ The present study examines the physical state and rehabilitation of those children who entered the programme between 1971 and 1978. These criteria meant that all had received treatment from a coordinated paediatric nephrology service and most had reached adulthood at the time of the study. Though most paediatricians now accept that children with end stage renal failure should be treated, the likely benefits of such lifelong treatment must include the possibility of an enjoyable and satisfying adult life if they are to outweigh the considerable burden of treatment. It was with this consideration in mind, as well as a desire to improve the rehabilitation of our patients, that this study was undertaken.

\section{Patients and methods}

Between January 1972 and June 197746 children between the ages of 4 and 14 years were accepted into the regular dialysis and transplant programme at Guy's Hospital. All had had at least one kidney transplanted. Thirty one were known to be alive in June 1985, one had been lost to follow up, and 14 $(31 \%)$ had died. Degree of renal function of those surviving was obtained from hospital records. The patient's heights were measured by a single observer using the same stadiometer.

The survivors were asked to complete a special questionnaire, designed to obtain factual information on education, employment, marital state, and psychiatric problems, and suspected areas of dissatisfaction within their social and personal lives. The questionnaire (appropriately modified) was also sent to 32 patients with diabetes of juvenile onset who had been treated at this hospital for a period spanning their growth into adulthood to provide a useful comparison with the patients with end stage renal failure who also had a chronic and potentially disabling disease requiring lifelong treatment. They differ, however, in that their treatment is less invasive and the risk of premature death lower. 


\section{Results}

Fourteen patients $(31 \%)$ died after entering the programme: five in the first year, two in each of the second and third years, one in each of the fourth and fifth years, two in the sixth year, and one in the tenth; 12 of the 14 occurred between 1972 and 1978 . The causes of death were known in 10 children: six died from septicaemia, and one each from acute pancreatitis, hyperkalaemia, sarcoma, and encephalopathy associated with cystinosis.

Table 1 shows the primary renal disease of all patients. The unusually large number of patients with cystinosis reflects the unit's role as a supraregional referral centre. In view of their peculiar growth and metabolic problems patients with cystinosis have been shown separately when their results were significantly different from the other subjects. The 31 survivors had been treated for an average of $10 \cdot 3$ years and had received a total of 48 renal

Table 1 Primary cause of end stage renal failure in 45 patients*

\begin{tabular}{ll}
\hline Diagnosis & No of patients \\
\hline Reflux nephropathy & 12 \\
Cystinosis & 7 \\
Focal segmental glomerulosclerosis & 6 \\
Schönlein Henoch disease & 5 \\
Familial nephritis & 4 \\
Chronic glomerulonephritis & 3 \\
Nephronophthisis & 3 \\
Haemolytic-uraemic syndrome & 1 \\
Polyarteritis & 1 \\
Dysplasia & 1 \\
Familial nephrotic syndrome & 1 \\
Malignant hypertension & 1 \\
\hline
\end{tabular}

${ }^{*}$ In one case no diagnosis was made.

Table 2 Comparison of patients with end stage renal failure and those with juvenile onset diabetes

\begin{tabular}{lll}
\hline & $\begin{array}{l}\text { No with end } \\
\text { stage renal } \\
\text { failure } \\
(n=31)\end{array}$ & $\begin{array}{l}\text { No with diabetes } \\
(n=17)\end{array}$ \\
\hline $\begin{array}{l}\text { Sex } \\
\text { male } \\
\text { female }\end{array}$ & $14(45 \%)$ & $6(35 \%)$ \\
$\begin{array}{l}\text { Average (range) age in } \\
\text { June 1985 (years) }\end{array}$ & 17 & 11 \\
$\begin{array}{l}\text { Average (range) duration } \\
\text { of disease (years) }\end{array}$ & $10(14-27)$ & $23(16-29)$ \\
\hline \begin{tabular}{l} 
Date of onset of disease \\
\hline
\end{tabular} & $1972-77$ & $12(5-26)$ \\
\hline
\end{tabular}

No significant differences between groups. transplants. Twenty six had stable, functioning grafts ( 22 with plasma creatinine concentrations of $<150 \mu \mathrm{mol} / \mathrm{l})$, four were receiving haemodialysis at home, and one haemodialysis in hospital. Fifteen of the 31 had not had more than 12 months of dialysis.

Twenty nine patients with renal disease and 17 diabetic patients responded to the questionnaire. Table 2 shows the age and sex distribution and duration of treatment. The smaller proportion of diabetic respondents implies an appreciable degree of self selection that might have produced an unrepresentative sample. We were unable to eradicate this problem, resulting in difficulties in interpretation of the data.

\section{GROWTH}

Height at the onset of end stage renal failure and at June 1985 (when 27 of the 31 were over 18 years old) was classified according to the number of standard deviations (SD) from the mean of normal children using the Tanner standards for the height of British children. ${ }^{2}$ Girls under 9 years old and boys under 11 were classified as prepubertal; these age divisions correspond to the average age of the onset of puberty in girls and boys, respectively. The mean heights attained are shown in table 3 . The changes in mean (SD) height for boys and girls are shown in the figure. The height at the onset of end stage renal failure was not obtained for three boys and three girls.

\section{DISABILITY}

Bone disease associated with end stage renal failure or its treatment occurred in five cases $(17 \%)$. All patients were able to walk unaided, though two were unable to run. None had cystinosis. Seven (23\%) had other disabilities or diseases, half of which were known associations of the primary renal disorder-for example, cystinosis and disorders of vision $(n=4)$. In the diabetic group $12 \%$ had an associated disability.

SOCIAL ACTIVITY, EDUCATION, AND EMPLOYMENT The special questionnaire provided a simple and subjective assessment of social activities, though the directive format may have encouraged a heightened sensitivity to potential areas of dissatisfaction. Nevertheless, $11(46 \%)$ of the group with end stage renal failure (excluding those with cystinosis) and 10 $(59 \%)$ of the diabetic patients, said that their social life had been adversely affected by their disease or its treatment. About half of those with end stage renal failure said this problem related to short stature, with obesity and the side effects of drugs playing a part for many. Specifically, 5 (45\%) were troubled by driving restrictions, and a similar 
Table 3 Heights achieved in patients with and without cystinosis

\begin{tabular}{llllll}
\hline$S D$ score & \multicolumn{2}{l}{ Boys $(n=14)$} & & \multirow{2}{*}{ Girls $(n=17)$} \\
\cline { 2 - 3 } & Without cystinosis & With cystinosis & & Without cystinosis & With cystinosis \\
\hline+2 to +3 & 1 & 0 & 0 & 0 \\
+1 to +2 & 0 & 0 & 0 & 0 \\
0 to +1 & 1 & 0 & & 0 \\
-1 to 0 & 2 & 0 & 2 & 0 \\
-2 to -1 & 1 & 0 & 4 & 0 \\
-3 to -2 & $2(1)$ & $2(2)$ & 2 & 0 \\
-4 to -3 & $3(1)$ & 0 & 1 & 0 \\
-5 to -4 & $2(1)$ & 0 & 0 & 1 \\
-6 to -5 & 0 & 0 & & 0 \\
\hline
\end{tabular}

All but three boys and one girl had reached final height; figures in parentheses are numbers of boys aged $<11$ and girls aged $<9$ at the beginning of the study.

proportion felt unable to take part in sports or holiday overseas when they wanted. Among the diabetics, travelling abroad $(6,60 \%)$, and attending organised social events $(4,40 \%)$, were the major areas of limitation. Four of the five survivors with cystinosis described adverse effects on their social life associated with their short stature and body shape. For them, driving restrictions were usual, though other 'social limitations' were only as common as in other diseases.

Tables 4 and 5 summarise educational achievement and employment records, respectively. In general, those with end stage renal failure compared favourably with the diabetics except that more failed

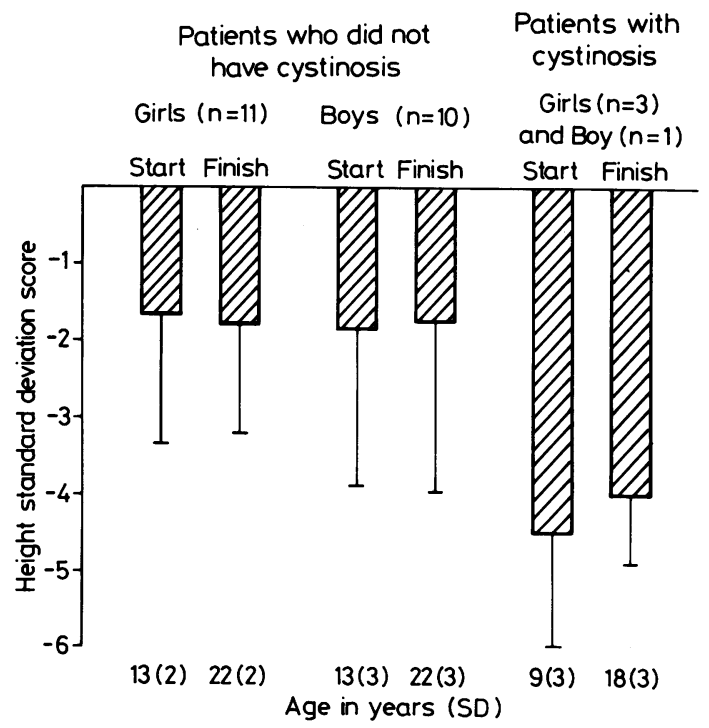

Figure Times of death after entering programme; patients with cystinosis shown separately. to attain school qualifications and employment. Only two of the 22 permanent job seekers with end stage renal failure had never had a job, however, and $13(59 \%)$ had kept either one or two jobs for a median of 5.6 years (range $0 \cdot 5-9 \cdot 5$ ). Among the job seekers with diabetes, $7(50 \%)$ had held one or two jobs for a median period of 6.0 years (range $0 \cdot 3-12 \cdot 0)$. The subgroup with cystinosis had achieved higher school academic standards than other children with end stage renal failure, although too few (two of five) had completed their education for us to note any effect on employment prospects.

The distribution of socioeconomic class (based on occupation $^{3}$ ) was similar between diabetics and those with renal disease: most were in class three. Six $(40 \%)$ of those with end stage renal failure and 5 $(33 \%)$ of the diabetics held jobs that were in a lower classification than those of their fathers. Four (26\%) diabetic patients had jobs with higher classifications but none of the patients with end stage renal failure had done so.

\section{ACCOMMODATION AND PERSONAL RELATIONSHIPS}

Data from subjects with end stage renal failure due to cystinosis were not significantly different from subjects with other renal diseases on the questions relating to independence from parents, personal relationships, perceived prejudice, and psychiatric disturbance, and the results are not, therefore, presented separately.

Table 6 shows the residential arrangements of patients 18 years or older at the time to the study. A more dominant preference to live with parents or relatives appears to exist in the group with end stage renal failure, but it should be noted that 13 of 17 $(76 \%)$ of the diabetics were either married $(4,23 \%)$ or having long term relationships $(9,53 \%)$, but only eight of $27(28 \%)$ of those with end stage renal failure had such relationships. 
Table 4 Comparison of educational achievement among groups studied

\begin{tabular}{|c|c|c|c|}
\hline \multirow{2}{*}{$\begin{array}{l}\text { Highest qualification } \\
\text { obtained }\end{array}$} & \multicolumn{3}{|c|}{ Patients with end stage renal failure } \\
\hline & $\begin{array}{l}\text { Cystinosis }(n=5) \\
\text { No }(\%)\end{array}$ & $\begin{array}{l}\text { Other diseasest }(n=21) \\
\text { No }(\%)\end{array}$ & $\begin{array}{l}\text { Diabetes }(n=17) \\
\text { No }(\%)\end{array}$ \\
\hline $\begin{array}{l}\text { General Certificate of Education: } \\
\text { Advanced level } \\
\text { Ordinary level }\end{array}$ & $\begin{array}{l}2(40)^{*} \\
2(40)^{*}\end{array}$ & $\begin{array}{l}2(10) \\
7(33)\end{array}$ & $\begin{array}{l}4(24) \\
5(29)\end{array}$ \\
\hline $\begin{array}{l}\text { Certificate of Secondary Education } \\
\text { None }\end{array}$ & $\begin{array}{l}0 \\
1(20)^{*}\end{array}$ & $\begin{array}{l}4(19) \\
8(38)\end{array}$ & $\begin{array}{l}6(35) \\
2(12)^{*}\end{array}$ \\
\hline
\end{tabular}

*One in each group still at school; †three patients did not answer this question.

Sexual difficulties were reported by five of the eight patients with renal disease in any form of long term relationship. The remaining 21 interpreted this question as not being applicable to themselves. By comparison, none of the diabetic patients reported sexual difficulties, and two girls each had a child. None of the three female patients with renal failure who had married had had children, though infertility was not perceived as a problem by any patient in either group.

Only four of $24(17 \%)$ of single patients with end stage renal failure over 16 years of age had a stable boyfriend or girlfriend compared with $8(89 \%)$ of single diabetics over the age of 16 , even though most considered such a relationship to be desirable.

Half of those in the group with end stage renal failure had not dated a member of the opposite sex in the three months before completing the question-

Table 5 Comparison of No employed in both groups

\begin{tabular}{lll}
\hline $\begin{array}{l}\text { Type of } \\
\text { employment }\end{array}$ & $\begin{array}{l}\text { Patients with end stage } \\
\text { renal failure }(n=24) \\
\text { No }(\%)\end{array}$ & $\begin{array}{l}\text { Diabetes } \\
(n=16) \\
\text { No }(\%)\end{array}$ \\
\hline Full time & $14(58)$ & $13(81)$ \\
Part time & $2(9)$ & $2(13)$ \\
Unemployed & $6(25)$ & $1(6)$ \\
Disabled & $2(8)$ & 0 \\
\hline
\end{tabular}

Table 6 Comparison of types of accommodation between both groups for those aged over 18

\begin{tabular}{lll}
\hline $\begin{array}{l}\text { Type of } \\
\text { accommodation }\end{array}$ & $\begin{array}{l}\text { Patients with end stage } \\
\text { renal failure (n=23) } \\
\text { No (\%) }\end{array}$ & $\begin{array}{l}\text { Diabetes } \\
(n=15) \\
\text { No (\%) }\end{array}$ \\
\hline $\begin{array}{l}\text { With parents or } \\
\text { relatives }\end{array}$ & $14(61)$ & $7(47)$ \\
$\begin{array}{l}\text { Married, or with } \\
\text { others }\end{array}$ & $8(35)$ & $7(47)$ \\
Alone & $1(4)$ & $1(6)$ \\
\hline
\end{tabular}

naire. The feeling of being a victim of prejudice in private and public relationships with others was expressed by $9(53 \%)$ diabetics and $20(71 \%)$ patients with end stage renal failure. Most grievances centred on the areas of job application and opportunity, and to a lesser degree, on obtaining life insurance and achieving satisfactory personal relations (especially with the opposite sex). This last was felt to be linked to poor public understanding of their disease and to the problems of short stature and (in the case of those with end stage renal failure) altered physical appearance.

Seven $(41 \%)$ of the diabetics and $10(34 \%)$ of those with end stage renal failure had seen a doctor for a persistent emotional or psychiatric problem during the five years preceding the study. Seven $(70 \%)$ of those with end stage renal failure had seen a psychiatrist, though only one was receiving treatment at the time of the study. No patient had been admitted to hospital for a psychiatric illness.

\section{Discussion}

The overall survival during the period of development of a full paediatric dialysis and transplant service had been disappointing. It should be recognised, however, that the actuarial five year patient survival has improved from $76 \%$ between 1968 and 1978 to $90 \%$ between 1975 and $1981 .{ }^{4}$ The present data describe a population of survivors of treatment for end stage renal failure in childhood of whom most had renal transplants that were functioning well and in whom physical rehabilitation had been excellent.

Unfortunately, a self selection process among the diabetic patients limited the size of the group for comparison with patients with end stage renal failure, and possibly their ability truly to represent the rehabilitation of diabetics as a whole. The diabetic patients had notably better education and employment records than those with end stage renal failure. Using similar criteria to our own, however, a 
recent study ${ }^{5}$ of 86 similarly aged diabetic patients treated in another large centre in Britain showed educational and employment performances similar to those attained by our subjects with renal disease. These and other data ${ }^{6}$ suggest that our group of diabetics may indeed be comparatively high achievers. In other areas of this study, however, and in particular those dealing with personal relationships and psychological wellbeing, they are probably more typical of the general diabetic population. ${ }^{7-9}$ Thus while accepting the limitations of our comparative data, we believe that they suggest several valid conclusions that should be discussed.

The education and employment records of patients with end stage renal failure, though not as good as the comparative group of diabetic subjects, are comparable with those reported in paediatric renal units in other countries. ${ }^{10} 11$ Nevertheless, the comparison with diabetics showed an association of higher unemployment with lower educational achievement among some patients with renal failure. The obvious conclusion is that the association is one of cause and effect. Clearly the intrusion of repeated hospital admissions and dialyses on a child's education needs to be minimised. Recently this consideration has been emphasised in this unit with the support of an energetic hospital school and its teachers. They provide education and support for children while they are in hospital and form an essential part of the treatment team.

The greatest problem among the subjects with renal disease was that of short stature. Even when patients with cystinosis were excluded from the analysis, 14 of 26 attained a final height greater than 2 SD below the mean. Their final height, however, compares favourably with that of European children treated for end stage renal failure before $1972 .{ }^{12}$ Though most of our patients had not grown well before entry to the treatment programme, only a few achieved appreciable catch up growth (including most of the children with cystinosis). Normal growth can be expected for many after transplantation, ${ }^{1}$ but other effects of treatment on physical appearance concerned our patients, in particular the development of a cushingoid appearance, obesity, and the ugliness of multiple surgical scars. As expected, patients with cystinosis were the shortest, and nearly all were conscious that their physical appearance was unsatisfactory. Nevertheless, they did not distort the findings for the whole group.

Patients often linked their restricted social life to a preoccupation with physical appearance-that is, short stature and obesity-although to some extent physical disability rather than physical appearance seemed to be the cause (for example, poor eyesight and the resultant inability to drive a motor vehicle). A study from the United States ${ }^{10}$ also reported that poor social adaptation within a restricted social life was common among patients with renal disease. Even more than a restricted social life, we observed a striking failure of our group to achieve lasting relationships as adults with members of the opposite sex. This was a major concern for most patients and contrasted unfavourably with the group of diabetics studied. The high rate of self reported sexual problems in those patients with renal disease who did achieve relationships raised further concern. We suspect that these data (as others have reported) are a reflection of low self esteem due partly to a poor body image. ${ }^{10} 13 \mathrm{In}$ this context it is important to note that many of our patients received invasive treatment during adolescence, a time when the issues of body image and self esteem are extremely important. We predict that when they become a source of anxious concern the disruption of normal psychosexual development is likely. Certainly our findings are consistent with others $^{14-16}$ and affirm the high incidence of psychosexual problems and poor personal relationships in those who have been treated for end stage renal failure during childhood and particularly during adolescence.

Although evidence of the usefulness of psychosocial support and intervention in chronic childhood illness is sparse ${ }^{17}$ and much seems to depend on family composition and personality traits, ${ }^{15}$ the results of the present study encourage us to increase the participation of patients and families as partners in the treatment. A higher priority now needs to be given to such measures in the hope that our patients can achieve more complete rehabilitation. To do this we now plan a more detailed study of our subjects using a structured social interview.

We thank the staff of the adult and paediatric renal units, and the diabetic unit at Guy's Hospital for their assistance.

\footnotetext{
References

1 Chantler C, Carter JE, Bewick M, et al. 10 years' experience with regular haemodialysis and renal transplantation. Arch Dis Child 1980;55:435-45.

2 Tanner JM, Whitehouse RH, Takaishi M. Standards from birth to maturity for height, weight, height velocity and weight velocity: British children, 1965. Part II. Arch Dis Child 1966;41:613-35.

3 Office of Population Censuses and Surveys. Classifications of occupations, 1970. London: HMSO.

${ }^{4}$ Rigden S, Bosque M, Benwick M, Haycock G, Chantler C. Survival of children with chronic renal failure. Arch Dis Child 1981;56:734.

5 Mok JYK, Laing IA, Farquhar JW. Young diabetics: memories, current lifestyles and attitudes. Diabetic Medicine 1984;1:227-30.
} 
6 Engel HO. Employment problems of diabetics. J Roy Soc Med 1984;77:1061-2.

7 Ahlfield JE, Soler NG, Marcus SD. The young adults with diabetes: impact of the disease on marriage and having children. Diabetes Care 1985;8:52-6.

${ }^{8}$ Mazze RS, Lucido D, Shamoon H. Psychological and social correlates of glycemic control. Diabetes Care 1984;7:360-6.

9 Lavigne JV, Traisman HS, Marr TJ, Chasnoff IJ. Parental perceptions of psychological adjustment. Diabetes Care 1982;5: 420-6.

10 Fine RN, Malekzadeh MH, Penisi AJ, et al. Long-term results of renal transplantation in children. Pediatrics 1978;61:641-50.

"Umeyama T, Hasegawa A, Ogawa $\mathrm{O}$, et al. Rehabilitation of pediatric renal allograft recipients: the present status and the problems. Transplant Proc 1984;16:1677-80.

12 Chantler C, Broyer M, Donckerwolcke, RA, et al. Growth and rehabilitation of long-term survivors of treatment for end-stage renal failure in childhood. In: Robinson B, ed. Proceedings of the European Dialysis and Transplant Association. Vol 18 Tunbridge Wells: Pitman Medical, 1981:329-39.

13 Winterborn MH. Optimum treatment of end-stage renal failure. Arch Dis Child 1983;58:164-6.
14 Bouras M, Raimbault G. The psychosocial consequences of renal disease and its treatment in children and adolescents: A follow-up study. In: Brodehl J, Ehrich JHH, eds. Paediatric nephrology. Berlin: Springer Verlag, 1983:196-200.

15 Korsch BM. Psychosocial aspects of children with chronic renal disease: Current issues in comprehensive care for children with chronic illnesses. In: Brodehl J, Ehrich, JHH, eds. Paediatric nephrology. Berlin: Springer Verlag, 1983:179-82.

${ }^{16}$ Klein SD, Simmons RG, Anderson CR. Chronic kidney disease and transplantation in childhood and adolescence. In: Blum RW, ed. Chronic illness and disabilities in childhood and adolescence. New York: Grune \& Stratton, 1984.

17 Pless IB, Satterwhite B. Chronic illness in childhood: Selection, activities and evaluation of non-professional family counsellors. Clin Pediatr 1972;11:403-10.

Correspondence and requests for reprints to Dr PH Henning, Renal Unit, Adelaide Children's Hospital, Adelaide, South Australia 5006.

Received 22 May 1987 